\title{
Níveis de adesão ao gasto público na função desporto e lazer por parte dos municípios brasileiros
}

\author{
Levels of adhesion to public expenditure in the sport \\ and leisure function by brazilian municipalities
}

\section{Niveles de adhesión al gasto público en la función deporte y ocio por parte de los municipios brasileños}

\author{
iD Edmilson Santos dos Santos \\ Universidade Federal do Vale do São Francisco, Petrolina, Pernambuco, Brasil \\ edmilson.santos@univasf.edu.br \\ iD 9 \\ Alessandra Dias Mendes \\ Instituto Federal de Educação, Ciência e Tecnologia de Brasília, Brasília, Distrito Federal, \\ Brasil \\ edmilson.santos@univasf.edu.br
}

Resumo: Nos últimos anos temos assistido ao surgimento de importantes análises sobre o financiamento das políticas de esporte e de lazer no Brasil por parte do governo federal. Já a participação dos municípios tem estado ausente da análise. Nesse sentido, o objetivo do estudo foi avaliar o nível de adesão dos municípios brasileiros ao gasto na Função Desporto e Lazer (FDL) e como objetivo específico avaliar os níveis de adesão por regiões e estados. Apesar dos estímulos do federalismo brasileiro à inação em matérias não reguladas por norma superior, há uma grande participação dos municípios na adesão a essa agenda. Porém, níveis diferenciados aparecem quando desagregamos as informações por região e estados. As regiões de maior desenvolvimento e seus estados apresentaram maior adesão ao gasto na FDL do que os municípios das regiões Norte e Nordeste.

Palavras-chave: Financiamento. Gasto Público. Políticas Públicas. Esporte. Lazer. 
Abstract: Over the last years we have been watching the emergence of important analyses about the funding of sport and leisure policies in Brazil on the part of the federal government. The participation of municipalities has been absent from these analyses. Thus, the objective of the study was to evaluate the level of adherence of the Brazilian municipalities to the expenditure on the Sports and Leisure Function (FDL). As a specific objective, we intended to assess the levels of adhesion per regions and states. Despite the incentives of Brazilian federalism to inaction in matters that are not regulated by a higher norm, there is great participation of municipalities in adhering to this agenda. However, different levels appear when we disaggregate information by region and state. More developed regions and their states presented higher adhesion to expenditure in the FDL than municipalities in regions North and Northeast.

Keywords: Funding. Public Expenditure. Public Policies. Sport. Leisure.

Resumen: En los últimos años hemos asistido al surgimiento de importantes análisis sobre el financiamiento de las políticas de deporte y de ocio en Brasil por parte del gobierno federal. La participación de los municipios ha estado ausente del análisis. En ese sentido, el objetivo del estudio fue evaluar el nivel de adhesión de los municipios brasileños al gasto en la Función Deporte y Ocio (FDL). Como objetivo específico, evaluar los niveles de adhesión por regiones y estados. A pesar de los estímulos del federalismo brasileño a la inacción en materias no reguladas por norma superior, hay una gran participación de los municipios en la adhesión a esa agenda. Sin embargo, los niveles diferenciados aparecen cuando desagregamos la información por región y estados. Las regiones de mayor desarrollo y sus estados presentaron mayor adhesión al gasto en la FDL que los municipios de las regiones Norte y Nordeste.

Palabras clave: Financiamiento. Gasto público. Políticas públicas. Deporte. Ocio.

Submetido em: 21/08/2018

Aceito em: 20/11/2019 
Níveis de adesão ao gasto público na função desporto e lazer...

Edmilson Santos dos Santos • Alessandra Dias Mendes

\section{Introdução}

Desde 2002 o Sistema de Informações Contábeis e Fiscais do Setor Público Brasileiro (SICONFI) da Secretaria do Tesouro Nacional, órgão vinculado ao Ministério da Fazenda, publica anualmente informações fiscais (receitas, despesas e investimentos) sobre os três níveis de governo: União, estados e Distrito Federal e municípios. Dentre as informações disponibilizadas estão as despesas com a Função Desporto e Lazer (FDL), que permitem acompanhar o desempenho dos governos no financiamento das políticas públicas de esporte e de lazer.

Diferente do que ocorre em outros países federalistas, a Constituição Federal de 1988 (CF/88) alçou os municípios ao nível de ente federado, construindo uma federação com três entes. Segundo Souza (2001), o Brasil se tornou a nação mais descentralizada do mundo. Portanto, há uma instância de governo mais próxima ao cidadão, com capacidade fiscal de gerir sua própria agenda política (descentralização bottom-up), sem precisar ser uma cadeia de transmissão das agendas dos níveis superiores (União ou estados ${ }^{1}$ realizam descentralização top-down) (ARRETCHE, 2004).

Carneiro e Almeida (2008) avaliam que os municípios foram os principais beneficiários da reforma fiscal da CF/88, já que passaram a dispor de recursos para promover suas agendas. Eles dispõem de liberdade para legislar sobre alguns tributos municipais e receberam percentual importante da receita do governo federal (via Fundo de Participação dos Municípios - FPM), a título de compensação financeira, para corrigir desigualdades. Esse último aspecto reconhece que as diferenças econômicas são um entrave à garantia de oferta mais equitativa de bens públicos (SOUZA, 2001; ARRETCHE, 1999).

Considerando que os 5.570 municípios brasileiros possuem enorme desigualdade econômica, que impacta na capacidade decisória (ARRETCHE, 2005), é possível supor que eles, principal-

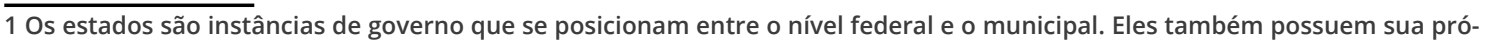
pria agenda política. União e estados estão acima dos municípios e podem descentralizar políticas em direção aos municípios. 
Níveis de adesão ao gasto público na função desporto e lazer...

Edmilson Santos dos Santos • Alessandra Dias Mendes

mente aqueles das regiões menos desenvolvidas do ponto de vista econômico e social (regiões Norte e Nordeste), tenham menos condições para ofertar sua própria agenda política. A inação (não fazer nada) política nas áreas de esporte e de lazer passa a ser uma opção legítima do poder executivo municipal em nossa engenharia federalista, visto que a aplicação do direito ao esporte ficou endereçada aos poderes legislativos de União, estados e municípios de forma concorrencial, conforme inciso VIII do Art. 24 da CF/88.

No entanto, essa capacidade de promover políticas que atendam aos interesses dos cidadãos está cerceada por atribuições estabelecidas pela CF/88 aos entes federados (MELO, 2005) e na capacidade fiscal.

Ao distribuir competências aos entes federados a CF/88 procurou garantir que cada um ficasse responsável pela oferta de atribuições privativas e comuns. No tocante ao esporte, apesar de garantir no artigo 217 da CF/88 o direito ao esporte como um dever de Estado, não foi indicada a instância de governo privativa, isto é, responsável por sua oferta, nem indicou competência comum aos entes federados.

Nesse sentido, como destaca Arretche (2003), não há garantia nenhuma que a estrutura de poder mais próxima ao cidadão, o poder público municipal, se torne responsivo às demandas da população. Mesmo considerando a maior capacidade de accountability na esfera do poder local, a descentralização produziu baixa responsabilização por parte dos municípios, como apontam Bonfim e Silva (2003).

O tema da implementação das políticas públicas de esporte e de lazer não tem sido explorado pela policy community da área no sentido de melhor compreender o impacto da engenharia federalista brasileira na descentralização da agenda. Suas análises têm focalizado principalmente a participação do governo federal no financiamento das políticas de esporte, como destacam os trabalhos de Castro, Scarpin e Souza (2017), Castro, Poffo e Souza 
Níveis de adesão ao gasto público na função desporto e lazer...

Edmilson Santos dos Santos • Alessandra Dias Mendes

(2016), Athayde, Mascarenhas e Salvador (2015), Corrêa et al. (2014), Almeida e Marchi Júnior (2010) e Veronez (2007). Poucos são os trabalhos que analisam, direta ou indiretamente, as relações federativas, como Diniz e Silva (2016) e Santos, Starepravo e Souza Neto (2015).

No âmbito municipal têm surgido alguns trabalhos que buscam melhor compreender a participação das prefeituras na oferta de políticas públicas de esporte e de lazer. Na dimensão focal, alguns trabalhos se destacam: Bettin, Peil e Melo (2018), analisaram a cidade de Pelotas/RS; Grasso e Isayama (2017), Santarém/ PA; Nascimento, Lazzarotti Filho e Inácio (2015), Aruanã/GO; Silva e Ávila (2014), Jequié/BA; Silva, Couto e Santos (2014), Ipiaú/BA; Venturim, Borges e Silva (2013), Vitória/ES; Silva et al. (2012), Ilhéus/ BA; e Brust, Baggio e Saldanha Filho (2006), Santa Maria/RS. Entre aqueles trabalhos que buscaram uma perspectiva panorâmica, temos: Santos, Canan e Starepravo (2018), que analisaram os projetos das prefeituras da Bahia; Mertins, Myskiw e Sanfelice (2016) analisaram 5 cidades do estado do Rio Grande do Sul; Azevedo (2015) analisou as prefeituras do estado do Acre; e Bankoff e Zamai (2011), as prefeituras de São Paulo.

Dada a diversidade das prefeituras brasileiras, ainda carecemos de abordagens que possam traduzir essa dimensão no que concerne à implementação de políticas públicas de esporte e de lazer. Diante desse cenário, torna-se importante avaliar o compromisso dos governos municipais com essa agenda através da identificação daqueles que realizaram gastos na Função Desporto e Lazer (FDL). Nesse sentido, o presente estudo teve por objetivo avaliar o nível de adesão dos municípios brasileiros à implementação de políticas de esporte e de lazer, utilizando como parâmetro o gasto no FDL. Como objetivo específico, está a avaliação dos níveis de adesão por regiões e estados. 
Níveis de adesão ao gasto público na função desporto e lazer...

Edmilson Santos dos Santos • Alessandra Dias Mendes

\section{Metodologia}

O presente estudo é caracterizado pela natureza descritiva e buscou, através dos dados fiscais dos municípios brasileiros, identificar aqueles que realizaram gastos na FDL de 2002 a 2011. A FDL é a unidade do setor público brasileiro que identifica o gasto em políticas de esporte e de lazer. Sua publicação é realizada pelo Sistema de Informações Contábeis e Fiscais do Setor Público Brasileiro. No período, o FDL dimensiona de forma agregada três níveis de gastos através das subfunções: Desporto Comunitário, de Desporto Rendimento, Lazer e demais subfunções do Desporto e do Lazer.

Desse modo, verificamos o orçamento dos 5.570 municípios brasileiros, de forma a analisar a adesão ao gasto na Função Desporto e Lazer de 2002 a 2011. O ano de 2002 se justifica por ser o primeiro ano que a Secretaria do Tesouro Nacional disponibilizou no Sistema de Informações Contábeis e Fiscais do Setor Público Brasileiro (SICONFI) os valores investidos pelos municípios na Função Desporto e Lazer (FDL). No ano de 2011 completou um ciclo de 10 anos de investimentos.

A Função Desporto e Lazer se refere à classificação do gasto orçamentário realizado em políticas de esporte e de lazer e foi estabelecida através da Portaria $\mathrm{n}^{\circ} 42$ do Ministério de Gestão e Orçamento (BRASIL, 1999). O registro do gasto é feito diretamente junto ao Tesouro Nacional no Sistema de Informações Contábeis e Fiscais do Setor Público Brasileiro (SICONFI).

Considerou-se como adesão o registro de valores na FDL no período de 2002 a 2011. Foram observados três níveis de análise. No primeiro, buscamos observar os níveis de adesão à FDL no âmbito nacional. Em seguida, contemplamos a escala regional considerando as cinco regiões brasileiras e, por último, a adesão por estado $(26)^{2}$.

2 A não inclusão do Distrito Federal (DF) se deve ao fato de ser de um ente federativo que não tem municípios, mas sim regiões administrativas ou cidades-satélites. O registro do gasto na FDL é feito pelo governo do DF. 
Níveis de adesão ao gasto público na função desporto e lazer...

Edmilson Santos dos Santos • Alessandra Dias Mendes

Para análise do trabalho foi constituído um banco de dados com informações provenientes de diferentes fontes. Os recursos investidos na Função Desporto e Lazer foram coletados junto ao site do Tesouro Nacional ${ }^{3}$ nos dados referentes às contas anuais no Sistema de Informações Contábeis e Fiscais do Setor Público Brasileiro (SICONFI), entre os dias 5 de março e 28 de outubro de 2016. A relação dos nomes dos municípios por estados e região foi coletada diretamente do site do Instituto Brasileiro de geografia e Estatística (IBGE).

\section{Resultados e Discussão}

Diante da elevada desigualdade na capacidade de oferta de política já destacada por Souza (2001) e da inexistência de constrangimentos no nível da federação à oferta de políticas públicas de esporte e de lazer, a inação aparece como uma hipótese robusta do comportamento dos municípios brasileiros. A Tabela 1 permite observar que esse elemento não foi suficiente para inibir os municípios de realizarem gastos na FDL.

Ao longo da década analisada, apesar da variação, houve crescimento do nível de adesão ao gasto na FDL. No primeiro ano de registro $78,56 \%$ dos municípios realizaram algum tipo de investimento e, no final da década, 89,59\%. O resultado parece consolidar a agenda de gasto na $F D L$, não se sabe se por uma preferência política do governo municipal ou por uma demanda social da população do município. Na primeira metade da década, a média de adesão foi de $81,23 \%$ dos municípios e, na segunda metade, $89,87 \%$. O crescimento também foi acompanhado de maior densidade de participação dos municípios à agenda de gasto na FDL na segunda metade do período.

Maior adesão, em tese, diminui os custos da reparação dessa desigualdade. Analisando a descentralização do Programa Segundo Tempo (PST), destinado a oferecer esporte educacional

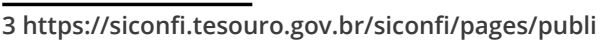


Níveis de adesão ao gasto público na função desporto e lazer...

Edmilson Santos dos Santos • Alessandra Dias Mendes

e lazer às populações vulneráveis, e formulada e financiada pelo governo federal, foi possível constatar que os incentivos ofertados não só não diminuíram a desigualdade como também produziram lacunas assistenciais (conjunto de municípios que não receberam o programa) na região Nordeste (SANTOS; STAREPRAVO; SOUZA NETO, 2015).

Tabela 1. Nível de adesão dos municípios brasileiros ao gasto da FDL de 2002 a 2011.

\begin{tabular}{ccccccccccc}
\hline Adesão & 2002 & 2003 & 2004 & 2005 & 2006 & 2007 & 2008 & 2009 & 2010 & 2011 \\
\hline $\mathrm{N}$ & 4375 & 4457 & 4308 & 4511 & 4967 & 4963 & 4997 & 5003 & 5073 & 4989 \\
$\%$ & 78,56 & 80,03 & 77,36 & 81 & 89,19 & 89,12 & 89,73 & 89,84 & 91,09 & 89,59 \\
\hline
\end{tabular}

Fonte: Dados da pesquisa.

Os municípios se diferem na capacidade de arrecadação e também no nível de desenvolvimento social. Por conta do processo histórico de desenvolvimento econômico e social, as regiões Norte e Nordeste tiveram mais dificuldades, inclusive pela falta da presença do Estado, de garantir maior equilíbrio na capacidade de oferta de políticas sociais. Os resultados encontrados na Tabela 2 destacam essa desigualdade.

Em todos os cenários, os municípios das regiões Norte e Nordeste apresentaram os menores níveis de participação na FDL, apesar do crescimento no nível de adesão durante a década. Enquanto as regiões Sul e Sudeste, com o maior índice de desenvolvimento humano municipal (PNUD/IPEA/FJP, 2016), consolidaram níveis acima de $90 \%$ a partir de 2005, a região Centro-Oeste alcançou tais patamares somente em 2009. É de se notar que as regiões Norte e Nordeste terminaram a década com níveis inferiores de adesão aos níveis iniciais alcançado pelas regiões Sul e Sudeste. 
Níveis de adesão ao gasto público na função desporto e lazer...

Edmilson Santos dos Santos • Alessandra Dias Mendes

Tabela 2. Nível de adesão dos municípios brasileiros no gasto da FDL de 2002 a 2011 por região (\%).

\begin{tabular}{ccccccccccc}
\hline Adesão & 2002 & 2003 & 2004 & 2005 & 2006 & 2007 & 2008 & 2009 & 2010 & 2011 \\
\hline S & 87,57 & 90,85 & 87,24 & 91,52 & 94,71 & 94,29 & 94,63 & 95,05 & 95,21 & 95,63 \\
SD & 86,57 & 89,03 & 88,67 & 91,55 & 96,04 & 96,58 & 97,54 & 96,82 & 97,30 & 96,16 \\
CO & 75,75 & 78,11 & 79,83 & 80,90 & 89,70 & 89,27 & 89,48 & 90,56 & 90,34 & 88,41 \\
ND & 68,39 & 68,95 & 63,88 & 66,83 & 80,71 & 80,49 & 81,16 & 81,88 & 84,17 & 82,50 \\
N & 68,44 & 64,22 & 60,44 & 70,67 & 82,44 & 82,00 & 82,22 & 81,11 & 85,56 & 78,67 \\
\hline
\end{tabular}

Fonte: Dados da pesquisa.

O Federalismo implica em diferenciação, combinada ou não com desigualdade (ARRETCHE, 2010). Portanto, não há de se exigir um comportamento igualitário nas agendas não reguladas por lei superior. Como podemos destacar na Tabela 3, a região Sul apresenta diferenças importantes no grau de adesão ao gasto na FDL. Enquanto os estados do Paraná (PR) e Santa Catarina (SC) apresentaram níveis de adesão superior a 90\% durante todo o período, o estado do Rio Grande do Sul (RS) só veio a alcançar esse percentual no final da primeira metade do período (2006).

Isso significa que, mesmo entre estados que comungam de um mesmo padrão de desenvolvimento econômico e social, é possível ocorrer distinções alocativas, algo constitutivo da federação. O RS termina a década com os níveis de adesão que o PR alcançou em 2006 e SC em 2005.

Tabela 3. Nível de adesão dos municípios da região Sul no gasto na FDL de 2002 a 2011.

\begin{tabular}{cccccccccccc}
\hline UF & Adesão & 2002 & 2003 & 2004 & 2005 & 2006 & 2007 & 2008 & 2009 & 2010 & 2011 \\
\hline PR & $\mathrm{N}$ & 361 & 371 & 362 & 371 & 387 & 381 & 382 & 384 & 386 & 389 \\
& $\%$ & 90,48 & 92,98 & 90,73 & 92,98 & 96,99 & 95,49 & 95,74 & 96,24 & 96,74 & 97,49 \\
\hline RS & $\mathrm{N}$ & 416 & 439 & 408 & 439 & 456 & 459 & 458 & 463 & 462 & 465 \\
& $\%$ & 83,70 & 88,33 & 82,09 & 88,33 & 91,75 & 92,35 & 92,15 & 93,16 & 92,96 & 93,56 \\
\hline \multirow{2}{*}{ SC } & $\mathrm{N}$ & 266 & 272 & 269 & 280 & 285 & 283 & 287 & 285 & 286 & 285 \\
& $\%$ & 90,17 & 92,20 & 91,19 & 94,92 & 96,61 & 95,93 & 97,29 & 96,61 & 96,95 & 96,61 \\
\hline
\end{tabular}

Fonte: Autoria própria. 
Níveis de adesão ao gasto público na função desporto e lazer...

Edmilson Santos dos Santos • Alessandra Dias Mendes

A região sudeste, responsável por cerca de 54,9\% do Produto Interno Bruto (PIB) nacional (IBGE, 2015), apresentou um padrão de adesão semelhante à região Sul, responsável por 16,4\% do PIB ${ }^{4}$, como pode ser observado na Tabela 4. Todos os estados alcançaram somente em 2008 níveis de adesão superiores a 90\%. Nesse aspecto, Minas Gerais (MG) e São Paulo (SP) se destacam. O primeiro alcançou esse percentual em 2004 e o segundo apresentou em quase todo o período (exceto em 2004) níveis de adesão superiores a $90 \%$.

Mesmo o estado que iniciou o período com adesões abaixo de 80\%, Espírito Santo (ES), em 2008 já alcançou 90\%. Os resultados encontrados na região permitem afirmar que a adesão à descentralização das políticas públicas de esporte e de lazer são robustas e permitem fazer como ilação que a capacidade financeira dos estados das regiões Sul e Sudeste pressiona por mais adesão aos gastos na FDL.

Tabela 4. Nível de adesão dos municípios da região Sudeste no gasto na FDL de 2002 a 2011. Onde “N" é no número de municípios que declararam gasto na FDL no período.

\begin{tabular}{cccccccccccc}
\hline UF & Adesão & 2002 & 2003 & 2004 & 2005 & 2006 & 2007 & 2008 & 2009 & 2010 & 2011 \\
\hline ES & $\mathrm{N}$ & 58 & 62 & 63 & 63 & 70 & 70 & 72 & 73 & 76 & 76 \\
& $\%$ & 74,36 & 79,49 & 80,77 & 80,77 & 89,74 & 89,74 & 92,31 & 93,59 & 97,44 & 97,44 \\
\hline MG & $\mathrm{N}$ & 719 & 745 & 775 & 789 & 826 & 828 & 833 & 833 & 833 & 816 \\
& $\%$ & 84,29 & 87,34 & 90,86 & 92,50 & 96,83 & 97,07 & 97,66 & 97,66 & 97,66 & 95,66 \\
\hline \multirow{2}{*}{$\mathrm{RJ}$} & $\mathrm{N}$ & 74 & 81 & 80 & 78 & 86 & 87 & 88 & 85 & 87 & 85 \\
& $\%$ & 80,43 & 88,04 & 86,96 & 84,78 & 93,48 & 94,57 & 95,65 & 92,39 & 94,57 & 92,39 \\
\hline SP & $\mathrm{N}$ & 593 & 597 & 561 & 597 & 620 & 626 & 634 & 624 & 627 & 627 \\
& $\%$ & 91,94 & 92,56 & 86,98 & 92,56 & 96,12 & 97,05 & 98,29 & 96,74 & 97,21 & 97,21 \\
\hline
\end{tabular}

Fonte: Autoria própria.

Nos estados do Centro-Oeste $\left(\mathrm{CO}^{5}\right)$ também percebemos certa diversificação no comportamento dos municípios dos estados que compõem a região (Tabela 5). O estado do Mato Grosso (MT)

\footnotetext{
4 Sete estados das regiões Sul e Sudeste são responsáveis por 71,3\% do PIB nacional, os outros 20 estados por 28,7\%. 5 A região Centro-Oeste é formada por três estados e o Distrito Federal, onde fica a capital do Brasil, que tem o mesmo status federativo que os estados.
} 
Níveis de adesão ao gasto público na função desporto e lazer...

Edmilson Santos dos Santos • Alessandra Dias Mendes

foi o que apresentou as melhores condições à descentralização do gasto na FDL. Na metade do período seus percentuais de adesão permaneceram acima dos $90 \%$, mesmo não iniciando com o maior percentual da década. O estado do Mato Grosso do Sul (MS) obteve o pior desempenho de largada e alcançou, nos anos de 2009 e 2010, adesão superior a 90\%, percentual que o estado de Goiás (GO) alcançou em 2007. A adesão acima de $80 \%$ foi alcançada por todos os estados no ano de 2005.

Tabela 5. Nível de adesão dos municípios da região Centro-Oeste no gasto na FDL de 2002 a 2011.

\begin{tabular}{cccccccccccc}
\hline UF & Adesão & 2002 & 2003 & 2004 & 2005 & 2006 & 2007 & 2008 & 2009 & 2010 & 2011 \\
\hline GO & $\mathrm{N}$ & 192 & 194 & 200 & 197 & 220 & 224 & 219 & 217 & 217 & 211 \\
& $\%$ & 78,05 & 78,86 & 81,30 & 80,08 & 89,43 & 91,06 & 89,02 & 88,21 & 88,21 & 85,77 \\
\hline MS & $\mathrm{N}$ & 56 & 60 & 60 & 67 & 69 & 68 & 70 & 73 & 72 & 70 \\
& $\%$ & 70,89 & 75,95 & 75,95 & 84,81 & 87,34 & 86,08 & 88,61 & 92,41 & 91,14 & 88,61 \\
\hline MT & $\mathrm{N}$ & 105 & 110 & 112 & 113 & 129 & 124 & 128 & 132 & 132 & 131 \\
& $\%$ & 74,47 & 78,01 & 79,43 & 80,14 & 91,49 & 87,94 & 90,78 & 93,62 & 93,62 & 92,91 \\
\hline
\end{tabular}

Fonte: Autoria própria.

A região Nordeste (ND) é a que apresenta o maior número de estados (9), portanto é de se esperar maior variação. Diferentemente das regiões Sul, Sudeste e Centro-Oeste, a grande maioria dos estados da região Nordeste $(66,66 \% ; n=6)$ iniciou a década com adesão abaixo de 70\%, sendo o estado do Sergipe (SE) o único da Região Nordeste com níveis de adesão abaixo de $40 \%$ (tabela 6).

Portanto, esses números iniciais demonstram o grau de dificuldade que os municípios da região têm de aderirem à agenda de gasto em Esporte e Lazer. É possível constatar que uma das regiões mais vulneráveis do Brasil tem dificuldade de garantir acesso a políticas públicas de esporte e de lazer.

O grande destaque dessa região fica por conta do Ceará (CE). Além de ser o único estado da região que obteve nível de adesão superior a $90 \%$ - esse valor foi alcançado em 2006 -, terminou a 
Níveis de adesão ao gasto público na função desporto e lazer...

Edmilson Santos dos Santos • Alessandra Dias Mendes

década com patamares de adesão superiores a estados das regiões de melhor desenvolvimento econômico e social. Esse resultado traduz uma desigualdade intrarregional. Durante os quatro primeiros anos da análise cinco tinham padrão de adesão abaixo dos $70 \%$.

Tabela 6. Nível de adesão dos municípios da região Nordeste no gasto na FDL de 2002 a 2011. Onde "N" é no número de municípios que declararam gasto na FDL no período.

\begin{tabular}{cccccccccccc}
\hline UF & Adesão & 2002 & 2003 & 2004 & 2005 & 2006 & 2007 & 2008 & 2009 & 2010 & 2011 \\
\hline AL & $\mathrm{N}$ & 65 & 68 & 65 & 66 & 82 & 72 & 83 & 85 & 90 & 82 \\
& $\%$ & 63,73 & 66,67 & 63,73 & 64,71 & 80,39 & 70,59 & 81,37 & 83,33 & 88,24 & 80,39 \\
\hline BA & $\mathrm{N}$ & 296 & 287 & 274 & 269 & 327 & 338 & 342 & 332 & 349 & 340 \\
& $\%$ & 70,98 & 68,82 & 65,71 & 64,51 & 78,42 & 81,06 & 82,01 & 79,62 & 83,69 & 81,53 \\
\hline CE & $\mathrm{N}$ & 159 & 161 & 151 & 146 & 170 & 166 & 173 & 171 & 174 & 173 \\
& $\%$ & 86,41 & 87,50 & 82,07 & 79,35 & 92,39 & 90,22 & 94,02 & 92,93 & 94,57 & 94,02 \\
\hline MA & $\mathrm{N}$ & 134 & 136 & 117 & 127 & 165 & 161 & 144 & 152 & 150 & 146 \\
& $\%$ & 61,75 & 62,67 & 53,92 & 58,53 & 76,04 & 74,19 & 66,36 & 70,05 & 69,12 & 67,28 \\
\hline PB & $\mathrm{N}$ & 146 & 145 & 124 & 147 & 178 & 182 & 189 & 183 & 191 & 187 \\
& $\%$ & 65,47 & 65,02 & 55,61 & 65,92 & 79,82 & 81,61 & 84,75 & 82,06 & 85,65 & 83,86 \\
\hline PE & $\mathrm{N}$ & 122 & 136 & 132 & 140 & 151 & 148 & 156 & 159 & 166 & 160 \\
& $\%$ & 65,95 & 73,51 & 71,35 & 75,68 & 81,62 & 80 & 84,32 & 85,95 & 89,73 & 86,49 \\
\hline PI & $\mathrm{N}$ & 172 & 177 & 162 & 170 & 199 & 194 & 191 & 197 & 193 & 190 \\
& $\%$ & 76,79 & 79,02 & 72,32 & 75,89 & 88,84 & 86,61 & 85,27 & 87,95 & 86,16 & 84,82 \\
\hline RN & $\mathrm{N}$ & 104 & 99 & 92 & 103 & 127 & 132 & 125 & 134 & 140 & 138 \\
& $\%$ & 62,28 & 59,28 & 55,09 & 61,68 & 76,05 & 79,04 & 74,85 & 80,24 & 83,83 & 82,63 \\
\hline SE & $\mathrm{N}$ & 29 & 28 & 29 & 31 & 49 & 51 & 53 & 56 & 57 & 64 \\
& $\%$ & 38,67 & 37,33 & 38,67 & 41,33 & 65,33 & 68,00 & 70,67 & 74,67 & 76 & 85,33 \\
\hline
\end{tabular}

Fonte: Autoria própria.

A região Norte também se destaca por apresentar alguns dos piores níveis de adesão ao gasto, como pode ser observado na Tabela 7. O estado do Tocantins se destaca em relação aos demais por ter iniciado a década com valores superiores a $80 \%$ e, mesmo depois de ter diminuído seu desempenho nos três anos posteriores, alcançou o corte de $90 \%$ de forma consolidada em 2005, à frente de estados das regiões mais desenvolvidas, como Rio Grande do Sul, Espírito Santo e Rio de Janeiro. 
Níveis de adesão ao gasto público na função desporto e lazer...

Edmilson Santos dos Santos • Alessandra Dias Mendes

A região tem as duas únicas experiências que não conseguiram garantir patamares superiores de adesão ao início da década: Amapá (AP) e Pará (PA). Depois do Tocantins, somente Rondônia (RO) alcançou de forma pontual valores de adesão superiores a $90 \%$ (2007/2008 e 2010). O Acre foi até 2007 sem conseguir elevar o nível de adesão ao gasto na FDL a 70\%. O pior resultado de todos os estados brasileiros foi o de Roraima em 2003, com adesão abaixo de $30 \%$.

Tabela 7. Nível de adesão dos municípios da região Norte no gasto na FDL de 2002 a 2011. Onde "N" é no número de municípios que declararam gasto na FDL no período.

\begin{tabular}{cccccccccccc}
\hline UF & Adesão & 2002 & 2003 & 2004 & 2005 & 2006 & 2007 & 2008 & 2009 & 2010 & 2011 \\
\hline AC & $\mathrm{N}$ & 11 & 12 & 11 & 9 & 13 & 13 & 17 & 12 & 17 & 16 \\
& $\%$ & 50 & 54,55 & 50 & 40,91 & 59,09 & 59,09 & 77,27 & 54,55 & 77,27 & 72,73 \\
\hline AM & $\mathrm{N}$ & 39 & 38 & 32 & 38 & 50 & 48 & 45 & 44 & 51 & 47 \\
& $\%$ & 62,90 & 61,29 & 51,61 & 61,29 & 80,65 & 77,42 & 72,58 & 70,97 & 82,26 & 75,81 \\
\hline AP & $\mathrm{N}$ & 10 & 7 & 5 & 9 & 14 & 12 & 12 & 12 & 11 & 9 \\
& $\%$ & 62,50 & 43,75 & 31,25 & 56,25 & 87,50 & 75 & 75 & 75 & 68,75 & 56,25 \\
\hline PA & $\mathrm{N}$ & 96 & 90 & 77 & 105 & 118 & 107 & 108 & 111 & 113 & 94 \\
& $\%$ & 66,67 & 62,50 & 53,47 & 72,92 & 81,94 & 74,31 & 75 & 77,08 & 78,47 & 65,28 \\
\hline RO & $\mathrm{N}$ & 31 & 33 & 33 & 38 & 41 & 47 & 48 & 46 & 49 & 45 \\
& $\%$ & 59,62 & 63,46 & 63,46 & 73,08 & 78,85 & 90,38 & 92,31 & 88,46 & 94,23 & 86,54 \\
\hline RR & $\mathrm{N}$ & 7 & 4 & 8 & 10 & 8 & 11 & 9 & 10 & 12 & 9 \\
& $\%$ & 46,67 & 26,67 & 53,33 & 66,67 & 53,33 & 73,33 & 60 & 66,67 & 80 & 60 \\
\hline TO & $\mathrm{N}$ & 114 & 105 & 106 & 109 & 127 & 131 & 131 & 130 & 132 & 134 \\
& $\%$ & 82,01 & 75,54 & 76,26 & 78,42 & 91,37 & 94,24 & 94,24 & 93,53 & 94,96 & 96,40 \\
\hline
\end{tabular}

Fonte: Autoria própria.

Os resultados até aqui analisados corroboram algumas observações sobre o desempenho das regiões na implementação de políticas sociais e revelam a potência da agenda de gasto na FDL em todas as regiões e estados brasileiros. 
Níveis de adesão ao gasto público na função desporto e lazer...

Edmilson Santos dos Santos • Alessandra Dias Mendes

\section{Conclusão}

A primeira afirmação importante do estudo é que, em linhas gerais, os municípios brasileiros não preferem a inação no que diz respeito ao gasto na FDL, apesar dos incentivos ${ }^{6}$ no nível da federação pressionarem por esse comportamento. Eles possuem um comportamento bastante ativo, indicando que outras variáveis atuam nesse cenário para atingir esse resultado.

No segundo aspecto, é possível observar desigualdades regionais na capacidade de adesão dos estados. As regiões Sul e Sudeste apresentam condições mais favoráveis e menos desiguais de adesão à FDL. Já as regiões Norte e Nordeste apresentam elevada desigualdade interna e níveis de adesão médio mais baixos do que os estados das regiões mais desenvolvidas, notadamente Sul e Sudeste. Esse resultado revela que a agenda de gasto na FDL é impactada por elementos regionais.

Esse quadro reforça a necessidade de maior participação do governo federal na oferta de incentivos à maior promoção de políticas públicas de esporte e de lazer nas regiões Norte e Nordeste, algo perfeitamente compatível com o que estabelece o inciso III do artigo 3 da CF/88: a promoção da equidade. Diante desse quadro, cabe ao governo federal aumentar os níveis de participação de suas políticas públicas de esporte e de lazer nas regiões Norte e Nordeste.

A agenda de pesquisa da policy community da área de educação física e esporte tem dado pouca importância à participação dos governos municipais na implementação de políticas públicas de esporte e de lazer. O presente estudo revelou existir elevada participação dos municípios na realização dessa agenda, mesmo existindo incentivos à inação.

6 Incentivos são os constrangimentos criados pela norma que podem fomentar uma ação ou estimular a inação. No caso aqui, os incentivos da federação são pela inação. Não há normas na federação brasileira que determinem a participação ativa dos municípios na oferta de políticas públicas esportivas. 
Níveis de adesão ao gasto público na função desporto e lazer...

Edmilson Santos dos Santos • Alessandra Dias Mendes

As análises descritivas têm por finalidade apresentar uma dada realidade ainda desconhecida. Muitos municípios brasileiros, mesmo diante da inexistência de constrangimentos no âmbito da federação, têm participado do financiamento das políticas públicas de esporte e de lazer. No entanto, desconhecemos que variáveis interferem nessa realidade. Portanto, a melhor compreensão desse fenômeno nos ajudará a ter um panorama mais ajustado das políticas públicas de esporte e de lazer no Brasil.

\section{Bibliografia}

ALMEIDA, B. S.; MARCHI JÚNIOR, W. O financiamento dos programas federais de esporte e lazer no Brasil (2004 a 2008).

Movimento, Porto Alegre, v. 16, n. 4, p. 73-92, 2010.

ARRETCHE, M. Federalismo e igualdade territorial: uma contradição em termos? Dados, Rio de Janeiro, v. 53, n. 3, p. 587-620, 2010.

ARRETCHE, M. Federalismo e políticas sociais no Brasil: problemas de coordenação e autonomia. São Paulo em Perspectiva, São Paulo, v. 18, n. 2, p. 17-26, 2004.

ARRETCHE, M. Financiamento federal e gestão local de políticas sociais: o difícil equilíbrio entre regulação, responsabilidade e autonomia. Ciência \& Saúde Coletiva, Rio de Janeiro, v. 8, n. 2, p. 331-345, 2003.

ARRETCHE, M. Políticas sociais no Brasil: descentralização em um Estado federativo. Revista Brasileira de Ciências Sociais, São Paulo, v.14, n.40, p.111-141, jun. 1999.

ARRETCHE, M. Quem taxa e quem gasta: a barganha federativa na federação brasileira. Revista de Sociologia e Política, v. 24, n. 1, p. 69-85, 2005.

ATHAYDE, P.; MASCARENHAS, F.; SALVADOR, E. Primeiras aproximações de uma análise do financiamento da política nacional de 
Níveis de adesão ao gasto público na função desporto e lazer...

Edmilson Santos dos Santos • Alessandra Dias Mendes

esporte e lazer no Governo Lula. Revista Brasileira de Ciências do Esporte, v. 37, n. 1, p. 2-10, 2015.

AZEVEDO, J. R. C. Políticas Públicas de Esporte e Lazer no Estado do Acre-Brasil. 231f. Tese (Doutorado em Ciências do Desporto) - Universidade do Porto, Porto/Portugal, 2015.

BANKOFF, A. D. P.; ZAMAI, C. A. Estudos sobre políticas públicas de esporte e lazer de prefeituras municipais do Estado de São Paulo. Conexões, Campinas, v. 9, n. 2, p. 70-79, 2011.

BETTIN, E. E.; PEIL, L. M. N.; MELO, M. P. Políticas públicas municipais de esporte, lazer e espaços públicos em Pelotas-RS na gestão 2009-2012. Pensar a Prática, Goiânia, v. 21, n. 1. 96-106, 2018.

BONFIM, W. L. S., SILVA, I. N. Instituições políticas, cidadania e participação: a mudança social ainda é possível? Rev. Sociol. Polít., Curitiba, v. 21, p. 109-123, nov. 2003.

BRASIL. Constituição da República Federativa do Brasil (1988). Diário Oficial [da] República Federativa do Brasil, Brasília, DF, 05 out. 1988. Disponível em: http://www.planalto.gov.br/ccivil_03/ Constituicao/Constituicao.htm. Acesso em: 15 jan. 2017.

BRASIL. Ministério do Planejamento, Orçamento e Gestão. Portaria n. 42, de 14 de abril de 1999. Diário Oficial [da] República Federativa do Brasil, Brasília, DF, 14 abr. 1999. Disponível em: ftp://ftp.fnde.gov.br/web/siope/leis/P42_ MPOG_14-041999.pdf. Acesso em: 20 fev. 2018.

BRASIL. Lei n. 4.320, de 17 de março de 1964: estatui normas gerais de direito financeiro para elaboração e controle dos orçamentos e balanços da união, dos estados, dos municípios e do Distrito Federal: Legislação complementar: Índice remissivo. Atlas, 2003.

BRUST, C.; BAGGIO, I. C.; SALDANHA FILHO, M. F. Repensar a gestão das políticas públicas de esporte e lazer: O caso de Santa Maria/RS. Motrivivência, Florianópolis, a. XVIII, n. 27, p. 179-192, 2006. 
CARNEIRO, L. P.; ALMEIDA, M. H. T. Definindo a arena política local: sistemas partidários municipais na federação brasileira. Dados, Rio de Janeiro, v. 51, n. 2, p. 403 a 432, 2008.

CASTRO, S. B. E.; SCARPIN, J. E.; SOUZA, D. L. Financiamento público e esporte educacional: uma análise do processo orçamentário do programa "Segundo Tempo" (2004-2011). Motrivivência, v. 29, n. 52, p. 136-156, 2017.

CASTRO, S. B. E.; POFFO, B. N.; SOUZA, D. L. Financiamento do esporte de rendimento no Brasil: programa "Brasil no Esporte de alto rendimento" (2004-2011). Revista Brasileira de Ciência e Movimento, Brasília, v. 24, n. 3, p. 146-157, 2016.

CORRÊA, A. J. et al. Financiamento do esporte olímpico de verão brasileiro: mapeamento inicial do programa Bolsa Atleta (20052011). Pensar a Prática, Goiânia, v. 17, p. 115, 2014.

DINIZ, R. S.; SILVA, L. P. O ICMS esportivo e o financiamento das políticas municipais de esporte em minas gerais. Movimento, Porto Alegre, v. 22, n. 4, 1223- 1236, out./dez. 2016.

GRASSO, R. P.; ISAYAMA, H. F. Financiamento e políticas públicas de esporte e lazer: uma análise da gestão no município de Santarém/PA (2005-2012). Revista Brasileira de Ciência e Movimento, Brasília, v. 25, n. 1, p. 151-167, 2017.

MELO, M. A. O sucesso inesperado das Reformas de Segunda Geração: federalismo, reformas constitucionais e política social. Dados, Rio de Janeiro, v. 48, n. 4, p. 845-889, 2005.

MERTINS, F. F.; MYSKIW, M.; SANFELICE, G. R. O Esporte e o Lazer na Estrutura Organizacional da Administração Pública Municipal. Licere, Belo Horizonte, v. 19, n. 3, p. 71-101, 2016.

NASCIMENTO, O. A. S.; LAZZAROTTI FILHO, A.; INÁCIO, H. L. D. As políticas públicas de lazer e esporte no município de Aruanã-GO. Pensar a Prática, Goiânia, v. 18, n. 4, out./dez. p. 864-879, 2015. PNUD, IPEA \& FJP. Desenvolvimento humano nas macrorregiões brasileiras. Brasília: PNUD, IPEA e FJP, 2016. 
Níveis de adesão ao gasto público na função desporto e lazer...

SANTOS, E. S.; STAREPRAVO, F. A.; SOUZA NETO, M. S. Programa Segundo Tempo e o vazio assistencial na região nordeste.

Movimento, Porto Alegre, v. 21, n. 3, 759-771, 2015.

SANTOS, E. S.; CANAN, F.; STAREPRAVO, F. A. Investimentos na função desporto e lazer por parte dos municípios da Bahia de 2002 a 2011. Journal of Physical Education, Maringá, v. 29, n. 1, p. 2-10, 2018.

SILVA, D. S., et al. Ações intersetoriais no planejamento político em esporte, lazer, cultura e turismo na gestão municipal de Ilhéus - BA. Licere, Belo Horizonte, v. 15, n. 1, p. 1-40, 2012.

SILVA, T. D.; ÁVILA, M. A. Análise da Estrutura Administrativa e Financeira Destinada ao Lazer no Município de Jequié-BA. Coleção Pesquisa em Educação Física, v. 13, p. 31-40, 2014. SILVA, T. D.; COUTO, A. M. S.; SANTOS, M. L. A. Analysis of the administrative structure and financial sport in IPIAU-BA county. Podium: Sport, Leisure and Tourism Review, São Paulo, v. 3, n. 3, p. 77-88, 2014.

SOUZA, C.. Federalismo e gasto social no Brasil: tensões e tendências. Lua Nova, São Paulo, v. 52, p. 5-28, 2001.

VENTURIM, L. F; BORGES, C. N.; SILVA, D. S. Estratégias de gestão pública na prefeitura de Vitória/ES? O PELC e a intersetorialidade das ações. Licere, Belo Horizonte, v. 16, n. 4, p. p. 1-38. dez. 2013. VERONEZ, L. F. C. O planejamento governamental e o orçamento do setor esportivo. In: XV Congresso Brasileiro de Ciências do Esporte e II Congresso Internacional de Ciências do Esporte, 2007, Anais... Recife. 2007. 
Níveis de adesão ao gasto público na função desporto e lazer...

Edmilson Santos dos Santos • Alessandra Dias Mendes

\section{Notas}

\section{Publisher}

Universidade Federal de Goiás. Faculdade de Educação Física e Dança. Publicação no Portal de Periódicos UFG. As ideias expressadas neste artigo são de responsabilidade de seus autores, não representando, necessariamente, a opinião dos editores ou da universidade. 